\title{
DOCTRINA SOBRE PRESUNCIÓN DE LEGITIMACION DEL ACTO ADMINISTRATIVO Y POSICIÓN DEL TRIBUNAL DE LO CONTENCIOSO ADMINISTRATIVO
}

Lorena Machi* Eliana Machi**

\begin{abstract}
RESUMEN. En el presente trabajo se trata de analizar el criterio actual del TCA sobre la presunción de legitimidad del acto administrativo, el cual no la admite desde hace un tiempo e incluso en alguna sentencia posterior a las que en el trabajo se indican. También se analiza otro tema sobre el cual no existe duda alguna ni cuestionamiento de ningún tipo, el relacionado con la actividad discrecional de la Administración. Sobre este segundo tema, entonces, la relevancia no se da en igual grado y existe abundante bibliografía y jurisprudencia. En lo que refiere a la presunción de legitimidad del acto administrativo, existen opiniones doctrinarias en contra y a favor de la misma, y estas se basan en analizar las normas que existen en nuestro ordenamientojurídico habiendo variado a lo largo de los años las mismas, por lo que en este trabajo se esbozará una serie de posiciones y sus fundamentos de forma breve.demás se citarán a vía de ejemplo sentencias del Tribunal de lo Contencioso Administrativo cuando postulaba la opinión a favor de la presunción de legitimidad y la que postula actualmente.
\end{abstract}

PALABRAS CLAVE. Presunción de legitimidad. Acto administrativo. presunción de ilegitimidad. Motivación. Acto administrativo, Actividad discrecional.

ABSTRACT. Throughout this paper we intend to analyze the current criterion of the Administrative Litigation Court relative to the presumption of legitimacy of the administrative act, which was not admitted for a while and even in some judgment subsequent to those stated herein. The paper further discusses another issue regarding which there is no doubt or questioning whatsoever, namely, the issue related to the

* Asesora Letrada de la Dirección Nacional de Seguridad Social del Ministerio de Trabajo y Seguridad Social. Correo electrónico: lorenayandira@hotmail.com

** Asesora Letrada de la Dirección Nacional de Energía del Ministerio de Industria, Energía y Minería. Correo electrónico: elianayandira@hotmail.com 
Administration's discretionary activity. On this second topic, relevance does not occur in the same degree and there is abundant bibliography and case law. With regards to the presumption of legitimacy of the administrative act, there are doctrinal opinions against and in favor, and these are based on analyzing existing rules in our legal system that have varied over the years, and throughout this paper a series of positions and their foundations will be briefly outlined. In addition, judgments of the Administrative Litigation Court will be cited as an example stating an opinion in favor of the presumption of legitimacy, which such Court is currently applying.

KEY WORDS. Presumption of legitimacy. Administrative act. Presumption of illegitimacy. Motivation of the administrative act. Discretionary activity.

\section{Definición: ¿qué se entiende por "presunción de legitimidad del Acto Administrativo"?}

Para comenzar por definir el tema que nos convoca podemos ver que expresa el Prof. Dr. Duran Martinez al respecto: "en general los autores entienden que los términos presunción de juridicidad, presunción de legalidad, presunción de validez o presunción de legitimidad son sinónimos: significan que se supone que el acto administrativo ha sido dictado con arreglo a derecho". ${ }^{1}$

Sin perjuicio de esto el autor en su artículo se propone distinguir los conceptos de perfección, validez, eficacia, estabilidad, firmeza, definitividad y ejecutoriedad.

Si vemos lo que ya sostuvimos en anterior trabajo respecto a lo que prevé el art 2 del Decreto $\mathrm{N}^{\circ}$ 500/91 existe la obligación de actuar por parte de la Administración conforme al principio de legalidad, tal como puede verse en el acápite de dicha norma la cual establece:

"La Administración Pública debe servir con objetividad los intereses generales con sometimiento pleno al Derecho. La expresión utilizada "debe” implica una obligación, se prevé que la Administración debe servir con objetividad pero también con sometimiento pleno al Derecho. De la misma se infiere el carácter imperativo de la norma. No existe discrecionalidad acá, no existe potestad en este caso, sino única y exclusivamente una obligación". ${ }^{2}$

¿Es conforme a dicho precepto que se establece que existe presunción de legitimidad de todo acto administrativo? Y ahora bien ¿Si ningún interesado o perjudicado alega la ilegitimidad del acto en vía recursiva o anulatoria, esto supone que es porque el acto se transformó en legítimo?.

Nuestra posición es un radical NO, y reiteramos lo que fuera dicho en trabajo: " $\boldsymbol{L} \boldsymbol{a}$ inexistencia de un perjudicado que alegue dicha ilegitimidad de un acto por medio de una interposición de recursos no enerva a la Administración del deber

1 Duran, Augusto. "La Presunción de Legitimidad del Acto Administrativo. Un Mito Innecesario y Pernicioso". En Revista de Derecho de la Universidad Católica del Uruguay, año 2007, № 2, pp 124.

2 Machi, Eliana. Machi, Lorena. "Revocación del Acto Administrativo de Oficio y su Conciliación con el Principio de Seguridad Jurídica”. En Revista de Derecho Público, no 50, Diciembre 2016, pp. 97-105. 
de ajustar sus normas conforme a Derecho, y además el transcurso del tiempo tampoco habilita a considerar que los actos dictados por la Administración se volvieron legitimos". (Lo que está en negrita nos pertenece).

Aclaramos y reiteramos esto ya que que si bien existe el deber de ajustarse a Derecho y por ende a dictar actos legítimos, este supuesto no habilita a considerar la existencia de una presunción de legitimidad del acto, porque bien sabemos que si existe el mecanismo de impugnación recursiva y anulatoria es porque existe una presunción de ilegitimidad del mismo, y no lo contrario. El acto no se vuelve legítimo porque no haya sido recurrido dentro del plazo legalmente establecido, ni anulado por el TCA. El acto debería de ser legítimo siempre, si es que la Administración cumple con los presupuestos legales previstos en nuestro ordenamiento jurídico, como lo es el art 2 del Decreto 500/91, pero la situación real muchas veces no condice con la que debería ser.

\section{Posición doctrinaria a favor de la presunción de ilegitimidad del acto administrativo.}

Al respecto podemos citar la posición sostenida por el Prof. Dr. Gordillo, cuando expresa que: “... es insalvablemente contradictorio afirmar que un acto deba o pueda presumirse legítimo si la persona que se enfrenta con él advierte inmediatamente que no es legítimo. Esa contradicción lógica ni siquiera podría ser superada por una hipotética norma legal expresa que asi lo dijera, pues alli tendriamos una pretendida presunción legal cuya irrazonabilidad parece manifiesta. En tal sentido cabría imaginar una norma que invocando el bien común o el interés público dijera que "Aunque encuentres un acto manifiestamente ilegítimo, debes comportarte como si fuera legítimo, pues la ley así lo impone." "Pero es claro que ello resulta irrazonable, por ende inconstitucional" (lo que está en negrita nos pertenece). ${ }^{3}$

Es más, no solo compartimos lo que expresa el autor en este párrafo citado, sino en lo que continúa expresando a continuación: "Es así manifiesta la debilidad o inexistencia del fundamento en que se hace reposar esa presunción de legitimidad: aun dejando de lado la vieja afirmación de la Corte, que los actos administrativos "por serlo" se presumen legítimos y atendiendo a la que ofrece alguna doctrina, se advierten sus limitaciones. Se afirma en la jurisprudencia que el fundamento radica en las garantias subjetivas $y$ objetivas que preceden a la emanación de los actos administrativos, lo que demuestra la tesis contraria. La realidad es el incumplimiento de las reglas del procedimiento, la dificultad práctica de tener vista de las actuaciones, la arbitrariedad con que el trámite se desenvuelve, la falta de cumplimiento de las normas que fijan los requisitos mínimos del acto, de audiencia previa, dictamen legal, sólida fundamentación, etc. La ausencia de alguno de ellos —aislado y a veces ni siquiera sumados-, no lleva a la nulidad judicial sino a su anulabilidad, saneable per se. Cabe pues concluir, de lege lata, que no están dadas en el derecho viviente las condiciones postuladas para la presunción de legitimidad amplia del acto administrativo...." ${ }^{4}$

3 Gordillo, Agustín. "Presunción de Legitimidad, Exigibilidad y Ejecutoriedad". En: Gordillo, A. Tratado de Derecho Administrativo y Obras Selectas. Fundación de Derecho Administrativo. 10 Edición, año 2011 Tomo 3. El acto administrativo. Capítulo 5. pp.V1-V55. Disponible en http:// www.gordillo.com/pdf_tomo3/capitulo5.pdf fecha de consulta 20/06/16.

${ }^{4}$ Gordillo, Agustín. op.cit. p.V10 
Claramente puede verse que el autor tampoco está del todo conforme con dicha posición doctrinaria y reconoce que en los hechos y en la práctica la realidad es que existen abundantes actos administrativos ilegítimos, los cuales incumplen requisitos legales esenciales y a pesar de eso, se dictan y surgen efectos, ya que mientras el acto no es revocado o anulado es válido. Y allí está la cuestión, es imposible sostener que un acto es legítimo porque no fue recurrido ni anulado, y por ende debe de ser cumplido y respetado, postulando la presunción de que dicho acto es legítimo (lo que está en negrita nos pertenece).

Si hiciéramos estadísticas de la cantidad de recursos administrativos y acciones de nulidad que existen como forma de impugnación de actos administrativos, y si contabilizáramos la cantidad de sentencias del TCA que salen favorables para el recurrente, nos daríamos verdaderamente cuenta que lo que abundan en los hechos son los actos ilegítimos, no legítimos. Entonces, ¿en donde queda la presunción de legitimidad del acto? La ilegitimidad es la regla cuando debería de ser la excepción.

\section{Análisis de posiciones doctrinarias a favor de la presunción de legitimidad del acto administrativo.}

Una posición contraria y por ende a favor de la existencia de dicha presunción de legitimidad es la postulada por Marienohoff, el cual al respecto ha dicho el Prof. Dr. Durán Martinez que: "aclara luego Marienhoff que esta presunción no es absoluta sino simple o relativa: puede ser desvirtuada por el interesado demostrando que el acto controvierte el orden juridico". 5

De lo que se infiere al analizar dicha expresión sería que la regla en cuestión radica en considerar que siempre estamos frente a un acto administrativo legítimo, pero como dicha presunción no es absoluta, sino que admite prueba en contrario, alcanzaría con que un interesado se presentase ante la Administración y ante elórgano Jurisdiccional después a alegar la vulneración de un acto contra una regla de derecho.

Pero ahora bien, que pasa cuando un interesado realmente no puede someterse a procedimientos extensos y costosos para intentar demostrar los perjuicios que le causa determinado acto que viola una regla de derecho. En este caso si fuéramos partidarias de la posición de la presunción de legitimidad podríamos sostener que el acto se presume legítimo ya que el mismo no logró ser impugnado.

Continuando con el artículo citado de Duran, el mismo dice que: "Propone entonces Marienhoff fundar la mencionada presunción de legitimidad en las garantías subjetivas y objetivas que preceden a la emanación de los actos administrativos. Y es aquí que cita a María Rivalta en cuanto dice que el acto administrativo procede de una autoridad pública que debe respetar la ley y es obra de funcionarios particularmente seleccionados y desinteresados, debe observar determinadas formalidades y es precedido de una serie de controles". ${ }^{6}$

5 Duran, A (2007). "La Presunción de Legitimidad del Acto Administrativo. Un Mito Innecesario y Pernicioso". En Revista de Derecho $N^{\circ} 2$ de Universidad Católica del Uruguay, 2, p.131.

6 Duran, Augusto. op.cit. p 141. 
Gordillo al respecto también se ha pronunciado diciendo que: ..."el acto administrativo puede ser producto de la sola voluntad de un solo individuo embriagado por el podery la omnipotencia de creerse semidiós, enviado providencial. Reconocerle a su capricho igual presunción que la de la ley, como para exigir su inmediato cumplimiento, sin información ni dictamen jurídico, sin consulta, sin discusión ni debate, sin audiencia previa, sin fundamentación normativa y fáctica razonable y suficiente, esto es el suicidio de la democracia" (lo que está en negrita nos pertenece). ${ }^{7}$

..."El dia que se cumpla el procedimiento administrativo de manera integral, de modo que un acto administrativo únicamente se dicte después del cumplimiento de una serie de trámites formales, con debida audiencia y prueba del interesado, con dictamen juridico previo, con fundamentos razonados de hecho $y$ de derecho, en condiciones de imparcialidad, etc., entonces podrá con algún dejo de razonabilidad recomenzarse la discusión de si al acto puede reconocérsele en tal circunstancia una presunción amplia de legitimidad. Y de todos modos ello no puede nunca amparar el acto manifiestamente viciado, por la inexcusable razón de que es imposible presumir que cierto acto es lo que manifiestamente no es." 8 (Lo que está en negrita nos pertenece).

En el trabajo de doctrina publicado por el Prof. Dr. Duran Martinez, sobre el tema de revocación de oficio por la administración de un acto administrativo precisa que, "CASSINELLI MUÑOZ y CAJARVILLE PELUFFO sostuvieron que la revocación sin recurso por razones de legitimidad no es un acto debido, sino discrecional. Tal discrecionalidad deriva de la existencia de plazos perentorios para recurrir. Sostener que la revocación sin recurso por razones de legitimidad es un acto debido equivale a dejar sin sentido los plazos perentorios previstos en la Constitución para recurrir. Pero esa revocación es posible si existen razones de interés público para disponerla; no basta para eso la ilegitimidad en sí misma” (lo que está en negrita nos pertenece). ${ }^{9}$

El Prof. Cajarville agregó después lo siguiente: “el plazo para recurrir parece perder su razón de ser si cualquier denuncia de ilegalidad, en cualquier momento, creara a cargo de la Administración el deber de revocar; la existencia de ese deber parece contradictoria con aquel plazo. Pero este enfoque tiene que ver con la firmeza del acto; y como se señaló en el planteamiento del tema aquí debe considerarse su estabilidad, atinente a la mutabilidad o inmutabilidad de la situación que ha creado; cuestión ajena a su firmeza, como lo es también su legitimidad o ilegitimidad; ambas atañen a las normas de fondo aplicables al acto y a la situación que ha creado". ${ }^{10}$

De lo transcripto puede verse el papel fundamental que se le da por parte de dichos autores al plazo legal de interposición de recursos frente a un acto administrativo,

Duran, Augusto. op. cit. p 142

Gordillo, Agustín. op.cit. p. V 11

9 CASSINELLI MUÑOZ, Horacio, “Jornadas de Derecho Comparado Chileno-Uruguayas”, en Revista de la Facultad de Derecho y Ciencias Sociales. Montevideo, año X, Números 1-2, pp. 334 y ss.

10 Duran Martinez, Augusto "Revocación de Oficio de un Acto Administrativo nulo creador de derechos cuyo vicio era conocido por el beneficiario" en Revista de Derecho Público año 26 n $^{\circ} 52$ diciembre 2017 , pág. 133.151." 
permitiendo suponer que la no interposición de los mismos dentro del plazo legal ya constituiría una potestad o facultad discrecional de la administración el revocar el acto ilegitimo o no, cuestión que no compartimos.

Como ya expresamos a veces la imposibilidad de interposición de recursos no implica un saneamiento de un acto administrativo ilegitimo, y si además de esto, la Administración es plenamente consciente de dicha ilegitimidad, tiene el deber no la potestad, a nuestro entender, de revocar el acto, puesto que conforme lo expresado anteriormente, en nuestro derecho está consagrada la presunción de ilegitimidad del acto y no lo contrario.

\section{4. "Presunción de legitimidad del acto administrativo" en el Derecho Positivo Vigente}

Nuestro Derecho Positivo no establece en ningún lado la presunción de legitimidad del acto administrativo, es más, todo lo contrario, existe a nivel legal la presunción de ilegitimidad del acto administrativo, la cual se encuentra prevista en el art 6 de la Ley $\mathrm{N}^{\circ}$ 15.869 de fecha 20 de junio de 1987, por cuanto expresa que: "Artículo $6^{\circ}$.- Vencido el plazo de ciento cincuenta dias o el de trescientos, en su caso, se deberán franquear, automáticamente, los recursos subsidiariamente interpuestos reputándose fictamente confirmado el acto impugnado. El vencimiento de los plazos a que se refiere el inciso anterior no exime al órgano competente para resolver el recurso de que se trate, de su obligación de dictar resolución sobre el mismo (artículo 318 de la Constitución). Si ésta no se produjera dentro de los sesenta dias siguientes a aquel en que se configuró la denegatoria ficta, la omisión se tendrá como presunción simple a favor de la pretensión del administrado en el momento de dictarse sentencia por el Tribunal, para el caso que se promoviere acción de nulidad" (lo que está en negrita nos pertenece).

La norma previamente citada fue modificada por el art 41 de la ley 17.292 de fecha 25 de enero de 2001 la cual cambió el plazo de sesenta días por el de treinta días, pudiéndose destacar que constituye a nuestro entender una garantía más para el interesado.

El Prof. Dr. Duran Martinez (en "Otra vez sobre la inexistente presunción de legitimidad del acto administrativo") ha dicho que: "Las presunciones son útiles en el ámbito jurídico solo en la medida en que no se distorsione la realidad. Como bien ha expresado De Freitas, el derecho fue concebido para el hombre real y no para el hombre presunto. La presunción de legitimidad del acto administrativo, tal como es tomada en el Uruguay, prescinde de la realidad y afecta o más bien, evita la argumentación, con lo que deslegitima la sentencia dictada con esa apoyuntura. Y la cosa es aún peor cuando, como sucede en el Uruguay, se invoca la presunción de legitimidad para desconocer la presunción de ilegitimidad impuesta por el art 6 de la ley $N^{\circ} 15869$, de 22 de junio de 1987, puesto que al hacerlo se desconoce abiertamente la ley”. ${ }^{11}$

De todos modos cabe remarcar que la disposición legal que establece la presunción de ilegitimidad del acto tiene un margen limitado, ya que la misma resulta de aplicación ante

11 Duran, Augusto. "Otra vez sobre la inexistente presunción de legalidad del acto administrativo". En Anuario de Derecho Constitucional Latinoamericano. XV año 2009. pp 845-861.disponible en http:/ /historico.juridicas.unam.mx/publica/librev/rev/dconstla/cont/2009/pr/pr47.pdf fecha de consulta 31/ $01 / 18$. 
un determinado supuesto, el cual es "para el caso que se promoviere acción de nulidad", lo que indirectamente posiciona una vez más al interesado en una situación engorrosa, consistente en tener que agotar la totalidad de los mecanismos legales previstos para impugnar el acto, recurriendo en última instancia a la acción de nulidad; y si el mismo no pudiera o no quisiera verse sometido a los extensos plazos y costos de un procedimiento anulatorio carecería de tener a su favor dicha presunción.

\section{Opinión de la Jurisprudencia del TCA respecto a las dos posiciones analizadas}

Se pueden distinguir dos momentos distintos respecto a la opinión sustentada por el Tribunal de lo Contencioso Administrativo en lo que refiere a la existencia de la presunción de legitimidad del acto administrativo. En un momento dado el mismo se pronunciaba a favor de la existencia de tal presunción, pero actualmente como consecuencia del cambio en la integración del Tribunal cambió también la posición sustentada. A fines explicativos citaremos algunas sentencias a continuación:

\section{i. Posición a favor de la presunción de legitimidad del acto administrativo:}

Sentencia TCA N ${ }^{\circ}$ 589/2003 de fecha 29 de octubre de 2003,

La misma se pronuncia en el siguiente sentido: "I) El acto administrativo tiene a su favor la presunción de legitimidad, tal como lo admite la doctrina (Marienhoff, "Tratado de Derecho Administrativo”, tomo II, pág. 372 a 378; conf. Rotondo Tornaría, Felipe "Manual de Derecho Administrativo", ed. Del Foro, Mont. 2000, pág. $211 N^{o}$ 259) y reiteradamente lo ha sostenido el Tribunal (véase, Anuario de Derecho Administrativo tomo V, pág. 189-190, casos $n^{\circ} 261$ a 267; tomo VI, pág. 240, casos $N^{\circ} 172$ a 175; y tomo VIII, pág. 381-382, casos 217 a 220, entre otros). Y por lo tanto quien invoca la ilegitimidad, tiene siempre la carga de la prueba correspondiente (arts. 58 y 104 del decreto ley $N^{o}$ 15.524; 283, 284, 313, 329 a 331 del C.Proc.Civil; y 137 y 139.1 del C.G.P.). A criterio del Tribunal, la actora no cumplió en forma suficiente con dicha carga probatoria, por lo cual se mantiene la presunción de legitimidad del acto y eso impone desestimar la pretensión de nulidad y la confirmación del mismo”.

-Sentencia No 61/2004 de fecha 18 de febrero de 2004 ha expresado que: "Sobre estas bases, e ingresando al fondo del asunto, se destaca que el acto administrativo tiene a su favor la presunción de legitimidad, tal como lo admite la doctrina (Marienhoff, "Tratado de Derecho Administrativo", tomo II, pág. 372 a 378; conf. Rotondo Tornaría, Felipe "Manual de Derecho Administrativo", ed. Del Foro, Mont. 2000, pág. 211 No. 259), y reiteradamente lo ha sostenido el Tribunal (véase, Anuario de Derecho Administrativo tomo V, pág. 189-190, casos No. 261 a 267; tomo VI, pág. 240, casos Nos. 172 a 175; y tomo VIII, pág. 381-382, casos 217 a 220, entre otros). Y por lo tanto quien invoca la ilegitimidad, tiene siempre la carga de la prueba correspondiente (arts. 58 y 104 del decreto ley No. 15.524; 283, 284, 313, 329 a 331 del C. Proc. Civil; y 137 y 139.1 del C.G.P.)”.

\section{ii. Posición a favor de la ilegitimidad del acto administrativo: Posición actual del TCA.}

Sentencia 703 del TCA de fecha 6 de octubre de 2015.

"Se reproducen en la especie, las condicionantes que determinan que opere la presunción legal de ilegitimidad del acto encausado (Cf. Sentencias 26/2014, 297/2013, 542/2012, 
415/2012, 315/2012, 813/2011, 175/2011, 323/2009, 18/2008, 214/2005 y 702/2004, entre otras)".

Sentencia No 624/2016 de fecha 18 de octubre de 2016.

Expresa que: "En efecto. Sobre tal presunción, el Tribunal ha expresado que: ... la parte demandada expresamente pretendió fundar la regularidad juridica del acto enjuiciado en base a la presunción de legalidad del acto administrativo, procede destacar que en la actualidad el Tribunal ha sostenido que dicho privilegio no goza de respaldo en nuestro ordenamiento jurídico. En tal sentido, recientemente se expresó”: “... es ciertamente discutible -por carencia de apoyatura normativa- el principio que admite la existencia de una presunción de legitimidad "iuris tantum", en beneficio de los actos dictados por la Administración, directriz reiteradamente relevada por jurisprudencia del Cuerpo en anteriores integraciones. (Sentencias Nos. 656/2001, 773/2006, 680/2007, 589/2007, etc.), cuya aplicación al presente pretende la demandada (fs. 21 vta. del ppal.). Porque como se ha dicho: "...la presunción de constitucionalidad de las leyes distorsiona los principios generales de derecho de mayor valor y fuerza y la Constitución en función de los intereses del legislador, y la presunción de legitimidad de los actos administrativos distorsiona esos mismos principios, la Constitución y la ley, en función de los intereses de la Administración, todo ello en definitiva en detrimento de los derechos humanos. Esas presunciones, pues -la de constitucionalidad de las leyes y la de legitimidad del acto administrativo-, no se adecuan al precepto de interpretación conforme a la Constitución”. (Durán Martínez, Augusto; "Otra vez sobre la inexistente presunción de legitimidad del acto administrativo”, Anuario de Derecho Constitucional Latinoamericano, 2009, $15^{\circ}$ año, Konrad Adenauer Stiftung, 2009, pág. 848). Debe de verse que la presunción comentada opera como un criterio apriorístico de valoración del accionar administrativo que, como tal, sin respaldo jurídico en nuestro ordenamiento logra privilegiar a uno de los sujetos del proceso, en detrimento de su contraparte inobservando la igualdad de los litigantes que informa y preside el proceso contencioso administrativo de anulación (art. 4 C.G.P., art. 104 del Decreto-Ley 15.524)..." (Sentencia 21/2013).

-Sentencia 426/2016 de fecha 21 de julio de 2016 dice: "En lo inicial se impone consignar que no se comparte la afirmación de que los actos administrativos gozan de una presunción de regularidad jurídica”. Y posteriormente repite lo pronunciado en la sentencia anteriormente citada.

Sentencia 356/2016 del TCA de fecha 16 de junio de 2016.

“... Por último, refuerza la viabilidad de la pretensión anulatoria actuada, la actitud asumida por la accionada, incumpliendo el órgano público con el deber jurídico que le ha sido atribuido, cuya inobservancia -bajo determinadas condicionantes- el legislador sancionó mediante la presunción de ilegitimidad en favor del interesado (art. $6^{\circ}$ de la Ley 15.869, en la redacción dada por el art. 41 de la Ley 17.292). En diversas ocasiones la Corporación ha relevado la referida presunción legal, cuya aplicación resulta preceptiva una vez verificado el presupuesto de hecho previsto en la norma (Cfme. Sentencias Nos. 796/2015, 725/2013, 124/2013, 11/2013, 751/2012, 315/2012, 285/2012, 196/2012, 189/2012, 813/2011, 175/2011, 323/2009, 18/2008, 214/2005, 702/2004, entre otras)”. "Como toda presunción simple, libera a su beneficiario ab initio de la carga probatoria de sus dichos, invirtiéndose ésta, debiendo la Administración procurar desplegar los medios 
probatorios hábiles y conducentes como única vía idónea para desvanecer el beneficio legal al que accedió el demandante”.

-Sentencia 198 del TCA de fecha 21 de abril de 2016: “... Invariablemente, en doctrina se ha señalado que el legislador uruguayo estableció una presunción de antijuridicidad en el supuesto editado por la norma, con severas críticas a la invocación reiterada de la presunción de legitimidad en jurisprudencia del Tribunal (así: DELPIAZZO, Carlos E.; "Derecho Administrativo General”, Vol. 1, Amalio M. Fernández, Montevideo, 2011, pág. 294), las que en su actual integración se consideran plenamente de recibo...... "Porque la presunción de legitimidad de los actos administrativos opera como un criterio apriorístico de valoración del accionar administrativo que, como tal, sin respaldo jurídico en nuestro ordenamiento logra privilegiar a uno de los sujetos del proceso, en detrimento de su contraparte inobservando el principio de la igualdad de los litigantes que informa $y$ preside el proceso contencioso administrativo de anulación (art. 4 C.G.P., art. 104 del Decreto-Ley 15.524), conforme se ha señalado por el Colegiado en las sentencias Nos. 415, 466 y 509/2012, 6 y 21/2013, entre otras, véase también el CONSIDERANDO XI de la Sentencia 427/2010 (lo que está en negrita nos pertenece)”.

\section{Conclusión.}

Producto del análisis efectuado de las dos posiciones sostenidas por la Doctrina administrativista y por la jurisprudencia del TCA vigente, podemos afirmar que compartimos las conclusiones arribadas por diversos autores respecto a la inexistencia de una presunción de legitimidad del acto administrativo. Creemos que nuestro propio sistema jurídico a través de las normas previamente citadas impide la existencia del mismo, ya que el motivo fundamental del sistema tuitivo en el Derecho Administrativo es de conceder las mayores garantías a los administrados, y la forma más razonable de hacerlo es reconociendo la existencia de la presunción de ilegitimidad del acto. Es mas de hecho la misma se encuentra establecida en nuestro Derecho Positivo, y resulta plenamente aceptada por la integración actual del Tribunal de lo Contencioso Administrativo.

Sin perjuicio de esto, destacamos que la consagración de dicho principio de presunción de ilegitimidad del acto constituye a nuestro entender una garantía eficiente para todo administrado, garantía que se encuentra más allá de la debida interposición de los recursos administrativos o no, y más allá de la interposición de la acción de nulidad.

Por cuanto, si dicha presunción es una garantía para el administrado, debiera suponerse que esta garantía persiste más allá de la no impugnación del acto, estando la Administración a nuestro entender obligada a revocar de oficio un acto administrativo ilegitimo, y no facultada a hacerlo como sostiene parte de la doctrina.

Las normas deben de dictarse conforme a derecho y conforme a nuestro ordenamiento jurídico, este sí es un precepto legal obligatorio, por ende si se observase la existencia de un acto administrativo que vulnerase esta prerrogativa, debería de ser revocado incluso de oficio por parte de la administración, a pesar de nunca haber sido recurrido. 


\section{BIBLIOGRAFÍA CONSULTADA.}

ARIAS, G. (2010). "A vueltas con la Discrecionalidad Administrativa". En Revista de Derecho Universidad Católica del Uruguay. $N^{o}$ 5. 11-26. Disponible en http://revistas.ucu.edu.uy/ index.php/revistadederecho/article/viewFile/814/816 Fecha de consulta 31/01/18.

ARTECONA,, D. "Discrecionalidad y Desviación de Poder. Necesidad y conveniencia de la consagración legal de potestades discrecionales a favor de la Administración”. En Revista de Facultad de Derecho, FDER. $N^{o} 30.45-54$. Disponible en http://revista.fder.edu.uy/index.php/ $\mathrm{rfd} /$ article/viewFile/85/89 . Fecha de consulta 31/01/2018.

CARJARVILLE, J P. (2008) "Sobre Derecho Administrativo". Segunda Edición ampliada. Montevideo. FCU. 50-53.

DURAN MARTINEZ A (2007). "La Presunción de Legitimidad del Acto Administrativo. Un Mito Innecesario y Pernicioso". En Revista de Derecho $N^{o} 2$ de Universidad Católica del Uruguay, 2, 124.

DURAN MARTINEZ, A.. "Revocación de Oficio de un Acto Administrativo nulo creador de derechos cuyo vicio era conocido por el beneficiario" en Revista de Derecho Público año $26 \mathrm{n}^{\circ} 52$ diciembre 2017, pág. 133.151.”

CASSINELLI MUÑOZ, H., "Jornadas de Derecho Comparado Chileno-Uruguayas", en Revista de la Facultad de Derecho y Ciencias Sociales. Montevideo, año X, Números 1-2, pp. 334 y ss.

DURAN MARTINEZ, A. (2009). "Otra vez sobre la inexistente presunción de legalidad del acto administrativo". En Anuario de Derecho Constitucional Latinoamericano. XV. 845-861.disponible en:http://historico.juridicas.unam.mx/publica/librev/rev/dconstla/cont/2009/pr/pr47.pdf. Fecha de consulta 20/06/17.

GORDILLO, A. (2011) "Presunción de Legitimidad, Exigibilidad y Ejecutoriedad". En: Gordillo, A. Tratado de Derecho Administrativo y Obras Selectas. Fundación de Derecho Administrativo. 10 Edición, Tomo 3. El acto administrativo. Capítulo 5. V1-V55. Disponible en http:// www.gordillo.com/pdf_tomo3/capitulo5.pdf Fecha de consulta 20/06/17.

GORDILLO, A. (2011) "Clasificación Jurídica de la Función Administrativa". En: Gordillo, A. Tratado de Derecho Administrativo y Obras Selectas. Fundación de Derecho Administrativo. 10 Edición, Tomo 1. Parte General.. Capítulo 10.X1-X41. Disponible en http://www.gordillo.com/ pdf_tomo1/capituloX.pdf Fecha de consulta 20/06/17.

MACHI, E. MACHI, L (2016). "Revocación del Acto Administrativo de Oficio y su Conciliación con el Principio de Seguridad Jurídica". En Revista de Derecho Público, $n^{\circ}$ 50, Diciembre 2016, $p$. 97-105.

PEREZ, V. (2009). "Motivación del Acto Administrativo: análisis de criterios jurisprudenciales y admisibilidad de su omisión alegando la reserva de las actuaciones". En Revista de Derecho de la Universidad de Montevideo. Año VIII. No 15. 37-54 Disponible en http:// revistaderecho.um.edu.uy/wp-content/uploads/2012/12/Perez-Benech-Motivacion-del-actoadministrativo-Analisis-de-criterios-jurisprudenciales-y-admisiblidad-de-su-omision-alegando-la-reserva-de-las-actuaciones.pdf Fecha de consulta 31/01/18.

RENATO VARGAS, A. "Arbitrariedad, Discrecionalidad y Libertad en la figura de la Discrecionalidad Administrativa”. En Revista Derecho y Cambio Social, Lima Perú. 1/04/2015. p 2. Disponible en http://www.derechoycambiosocial.com/revista040/ARBITRARIEDAD_ DISCRECIONALIDAD_Y_LIBERTAD.pdf. Fecha de consulta 31/1/18.

SAYAGUÉS LASO, E. “Tratado de Derecho Administrativo". 9. edición puesta al día a 2010 por Daniel Hugo Martins. Montevideo. FCU. 419-420.

Fecha de recepción: 17 marzo 2019

Fecha de aceptación: 10 abril 2019. 